\title{
ОБ АБСОЛЮТНОМ ВОЗРАСТЕ ВТОРОГО ПОЗДНЕПЛЕЙСТОЦЕНОВОГО МЕЖЛЕДНИКОВЬЯ НА ТЕРРИТОРИИ СЕВЕРО-ЗАПАДНОИ ЧАСТИ РУССКОЙ РАВНИНЫ
}

Геохронологическое расчленение позднего плейстоцена вызывает среди геологов-четвертичников большие споры. В последнем десятилетии, благодаря усовершенствованию радиоуглеродного метода и расширению номенклатуры датируемых объектов, произведены многочисленные анализы погребенных озерно-болотных отложений с возрастами до 63000 лет (Арсланов, 1966). Однако в связи с появлением все новых и новых датировок выявляются трудности при их интерпретации и сопоставления. Изотопный анализ, как известно, дает только сведения о физико-химической обстановке среды, которые при учитывании определенных предпосылок используются для определения возраста. Незнание или невозможность оценить все влияющие факторы могут сильно исказить истинные возрасты. С особенно большой осторожностью надо интерпретировать данные анализа древних образцов, при которых уже ничтожные загрязнения могут вызвать очень большие расхождения. Хотя использованием современных методов и аппаратуры можно довести возрастной предел радиоуглеродного метода даже до 70000 лет (Haring и др., 1958), вряд ли удастся на основе этого метода однозначно разработать геохронологию в таких возрастных пределах. Одной из главных тормозящих причин является относительно низкий уровень знаний о генезисе и свойствах гумусовых веществ, а также о сущности вторичных процессов, возникающих при обработке образцов.

Использование единичных датировок без учета конкретных геологических данных, а также физической сущности изменения природных процессов является основной причиной возникновения в настоящее время разных геохронологических схем расчленения позднего плейстоцена.

Ниже приводятся результаты изучения некоторых разрезов, датирование которых проведено главным образом автором в лаборатории Ин-та зоологии и ботаники АН ЭССР и которые существенны при разработке геохронологической схемы позднего плейстоцена. Важное значение среди них имеет разрез Карукюла, расположенный в юго-западной части Эстонской ССР. Данный разрез всесторонне изучен в течение нескольких десятилетий (Орвику, 1958; Орвику, Пиррус, 1965; Пуннинг и др., 1967; Заррина, 1970; Каяк и др., 1970 и др.) и здесь нет необходимости останавливаться на геологии этого разреза. Ограничимся лишь таблицей полученных и опубликованных до сих пор датировок по $\mathrm{C}^{14}$ для этого разреза. 


\begin{tabular}{|c|c|c|c|}
\hline $\begin{array}{l}\text { Глубина } \\
\text { взятия, } \leadsto\end{array}$ & Материал & $\begin{array}{l}\text { Возраст } \\
\text { по } \mathrm{C}^{14}\end{array}$ & $\begin{array}{c}\text { Лаб. индекс } \\
\text { и № образца }\end{array}$ \\
\hline $\begin{array}{c}150-170 \\
165 \\
205 \\
150-170 \\
195-215 \\
230 \\
235-255 \\
170-190 \\
? \\
149-164\end{array}$ & $\begin{array}{l}\text { Древесина } \\
\text { Торф" } \\
\text { " } \\
\text { Сапропелит } \\
\text { Торф и древесина } \\
\text { Торф }\end{array}$ & $\begin{array}{l}33450 \pm 800 \\
40800 \pm 700 \\
47800 \pm 1100 \\
48100 \pm 1700 \\
48100 \pm 1650 \\
48860 \pm 1200 \\
\geqslant 45500 \\
\geqslant 52780 \\
\geqslant 54400 \\
\geqslant 33000\end{array}$ & $\begin{array}{l}\text { TA-99 } \\
\text { TA-275 } \\
\text { TA-276 } \\
\text { TA-100 } \\
\text { TA-101 } \\
\text { TA-277 } \\
\text { TA-106 } \\
\text { ЛY-44 } \\
\text { ЛУ-68 } \\
\text { Mo-375 }\end{array}$ \\
\hline
\end{tabular}

Образцы, датированные в лаборатории геобиохимии Ин-та зоологии и ботаники АН ЭССР, отобраны из двух хорошо документированных и изученных разрезов (Каяк и др., 1970).

Несмотря на большое количество конечных датировок из разреза Карукюла, возраст этой межледниковой толщи нельзя считать еще окончательно установленным, так как полученные возрасты находятся на границе возможности радиоуглеродного метода. Вполне возможно, что нижний предел карукюлаского межледниковья в широком понимании может доходить до возрастных значений, приписываемых в настоящее время брерупскому интерстадиалу (Каяк и др., 1970).

Определенный интерес при обосновании второго позднеплейстоценового потепления имеет также разрез Пээду, расположенный в северозападной части возвышенности Отепя. По спорово-пыльцевым данным Э. Лийвранд этот разрез имеет некоторые черты сходства с межморенными отложениями разреза Карукюла. Так как в правильности первой нашей датировки $39180 \pm 1960$ лет (ТА-136) появились сомнения (Пуннинг, 1969), то органогенные отложения из-под плотной морены (мощность 6 м) и песков $(1,4 \mu)$ недавно были подвергнуты повторному радиоуглеродному анализу.

Были получены следующие результаты: ТА-254 (основной материал

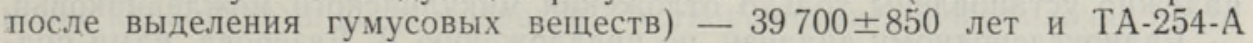
(выделенные гумусовые вещества) - $31200 \pm 800$ лет (Пуннинг, 1970).

Полученные датировки весьма близки к датировкам отложений разреза Гражданский проспект в г. Ленинграде, который был предложен (Вигдорчик и др., 1970а) стратотипом средневалдайского потепления. Впоследствии исследователи, изучившие разрез Гражданский проспект, повысили ранг потепления на межледниковье с ориентировочной продолжительностью от 25 до 50 тыс. лет (Вигдорчик и др., 1970б).

Радиоуглеродные датировки торфа из верхней и нижней прослоек межморенного комплекса разреза Гражданский проспект Х. Арслановым получены соответственно $39800 \pm 800$ (ЛУ-63) и $40380 \pm 800$ (ЛУ-22) лет. В спорово-пыльцевой диаграмме, по данным анализа Е. Спиридоновой, в нижней части того же комплекса господствует пыльца перигляциальной растительности, а в верхней - пыльца березы, сосны и ели (Вигдорчик и др., 1970a).

Итак, климатические условия при формировании соответствующих отложений в данном месте были несколько более суровыми, чем во время формирования органогенных отложений Карукюла и Пээду. Такое сравнение, однако, не совсем корректно, так как отложения в разрезе Карукюла представлены органогенным материалом, в то время как в разрезе Гражданский проспект -- кластическими отложениями, где пыльца, 
по-видимому, является в значительной мере переотложенной. Это, на наш взгляд, не позволяет рассматривать Гражданский проспект в качестве стратотипа.

В средневалдайском теплом интервале (в карукюлаское время) накопились также озерно-болотные стложения на Присухоньской низине. Прослойки торфа в суглинке здесь перекрыты озерно-ледниковыми отложениями максимальной стадии (?) валдайского оледенения и имеют сходные спорово-пыльцевые характеристики с отложениями разюеза Гражданский проспект. Возраст образца, отобранного из скважины № 257 на р. Сухоне с глубины 25,6-26,3 м, оказался по $C^{14} 33900 \pm$ \pm 300 лет (ТА-274). Однако не исключена возможность загрязнения материала образца из-за несоблюдения правил отбора.* Это весьма вероятно, учитывая, что датирование образцов из этого разреза в лаборатории ЛГУ Х. Арслановым дали более древние результаты: ЛУ-93 (образец с глубины 19,75-20,0 м) - $41100 \pm 1500$ и JУУ-94 (с глубины $20,0-20,2$ м) - $40800 \pm 1900$ лет (Ауслендер и др., 1970).

Все эти определения говорят в пользу существования на Русской равнине длительного теплового ннтервала, который, судя по палеонтологическим данным, имеет ранг межледниковья. В пользу такого вывода отчетливо говорит также находка на севере Финляндии подморенного торфяника возрастом $45400 \pm 2000$ лет (Korpela, 1969). Это значит, что ледники Скандинавского оледенения во время средневалдайского потепления отступали далеко на север и могли существовать только в Скандинавских горах.

В связи с приведенными данными немалый интерес представляют датировки раковин из трансгрессивных морских отложений средневалдайского потепления Кольского полуострова. Данный район имеет большое значение для понимания событий в позднем плейстоцене и после проведения дальнейших тщательных комплексных исследований позволит более уверенно увязать между собой плейстоценовые разрезы всего севера Евразии.

Разрезы с фауной моллюсков на территории Кольского полуострова до сих пор являются объектами оживленных дискуссий. По мнению многих исследователей (Апухтин, 1967; Арманд и др., 1969 и др.), здесь надежно установлены только отложения микулинского межледниковья.

Радиоуглеродному анализу, по предложению В. Евзерова, нами подвергались раковины из разрезов на рр. Чапома и Поноя. Разрез Чапома находится на 3,5 к.и выше устья р. Чапома. Морские межледниковые отложения залегают** на красно-бурой суглинистой морене и имеют общую мощность около $10 \mu$. В нижней части комплекса встречается множество крупных створок и обломков раковин. Их радиоуглеродный возраст $34500 \pm 450$ лет (ТА-270). По данным М. Лавровой (1960), определенные здесь виды ныне распространены только в юго-западной части Баренцового моря, где среднегодовая температура воды на $3-4^{\circ}$ выше, чем в районе отбора образцов. Это говорит в пользу межледникового характера осадков разреза Чапома, накопившихся в период трансгрессии моря. Палинологические данные указывают на изменение растительности от лесотундровой к лесной и вновь к лесотундровой (Евзеров, 1970).

Разрез Поной находится на левом берегу одноименной реки напротив пос. Поной. Морские межледниковые отложения представлены

* Частное сообщение В. Ауслендера и М. Вигдорчика.

** Описание по частному сообщению В. Евзерова.

*** Описание по частному сообщению В. Евзерова. 
разнозернистыми песчаными отложениями общей мощностью около $18 \mu$ и покрыты отложениями осыпей мощностью 2,5 $\mu$. Створки раковин встречаются на глубине около $4,5 \mu$ и особенно часто в ннтервале 9-11 м. По данным С. Стрелкова ****, здесь встречается 26 видов моллюсков, среди которых можно огметить Cyprina islandica L., Myatella arctica L., Astarte borealis Chemn., Chlamus islandicus Müll., Dentalium entalis L., Cardium edule L. и другие, указывающие на межледниковые условиях их обитания.

Образец для определения возраста отобран В. Евзеровым из регрессивной серии песчаных отложений с глубины 5-10,5 м (Евзеров, 1970).

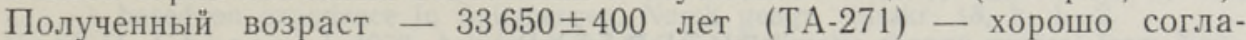
суется с датировкой из разреза Чапома. Этим подтверждается предположение (Евзеров, 1970), по которому в обоих разрезах анализировались горизонты, сформировавшиеся в начале регрессии моря, а датированные слои накоплялись в середине межледникового времени.

В связи с опубликованием этих датировок, полученных на основе довольно редко используемого в радиоуглеродной практике материала - раковин моллюсков - целесообразно коротко остановиться на методических особенностях и надежности полученных датировок.

Қак известно, раковины моллюсков формируются из растворенных в воде $\mathrm{CO}_{3}$ и $\mathrm{HCO}_{3}^{-}$. Неоднородность изотопного состава углерода, находящегося в разных частях обменного резервуара, может вызывать существенные ошибки при определении возрастов раковин моллюсков, особенно из пресноводных водоемов с жесткой водой. Возможные отклонения концентрации $\mathrm{C}^{14}$ из-за изотопного фракционирования могут достигать от -20 до $+4 \%$ (Broecker, Kulp, 1956), что влечет «удревнение» образцов на 1800 лет. На основе обобщения обширной литературы Н. Кинд и В. Алексеев (1963) находят, что «удревнение» возраста раковнн морских моллюсков, формирующихся на небольших глубинах, не превышает нескольких сотен лет.

Что касается изменения первоначального изотопного состава (кроме радиоактивного распада) образцов, то, версятно, не исключен также изотопный обмен после их захоронения, но оценить этот фактор очень трудно. Большую опасность после захоронения представляет и загрязнение карбонатами иного возраста. Растворение внешней оболочки раковин и использование только средней, основной части в большой степени исключает этот фактор. Следует также отметить, что раковинный материал для определения возраста успешно используют в Упсалаской лаборатории (Olsson, Blake, 1961-1962).

Для определения возраста нами были отобраны крупные, целиком сохранившиеся створки раковин. Разбавленной соляной кислотой при встряхивании растворяли внешние части створок (около $25 \%$ общего веса). После этого створки ополаскивали дистиллированной водой, высушивали, измельчали и растворяли в разбавленной соляной кислоте, причем первую порцию ( 20\%) полученного углекислого газа выпускали. Из остального газа через карбид лития синтезировали бензол (Ильвес и др., 1968), в котором и определяли активность $\mathrm{C}^{14}$.

В целях методического контроля нами определялся возраст створок Cyprina islandica L., отобранных Б. Кошечкиным из разреза Эйна на п-ове Рыбачий. Полученный возраст $6480 \pm 60$ (ТА-261) хорошо совпадает с предполагаемым 6500-6600 (Marthinussen, 1962).

Учитывая вышеизложенное, можно полагать, что полученные датировки довольно достоверны и отклонение от истинных значений вряд ли

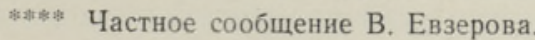


превышает несколько тысяч лет. Если это так, то получены еще одни новые и очень ценные доказательства в пользу выделения второгопозднеплейстоценового межледниковья в северо-восточной части Европы, которое сопровождалось крупным эвстатическим поднятием уровня моря. Такое поднятие в интервале от 50 до 30 тыс. лет назад отмечено многими исследователями (Карлстрём, 1966; Кинд, 1969 и др.). Нужно отметить еще то, что такие данные получены не только для северного, но также и для южного полушария (Veek, Chappel, 1970).

\section{ЛИ ТЕ РА Т У РА}

А п у х тин Н. И. 1957. Стратиграфия четвертичных отложений Кольского полуостроваз и Северной Қарелии по новейшим исследованиям. Мат-лы по геол. и полезн. ископ. Северо-Запада СССР, вып. 1. Л.

А м м ндА. Д., А м манд Н. Н., Гр а е М. К., Евзеров В. Я., Л ебедева Р. М. 1969. Сводная стратиграфическая схема четвертичных (антропогеновых) отложений Кольского полуострова в свете новейших данных. В сб.: Основные проблемы геоморфологии и стратиграфин антропогена Кольского полуострова. Л.

А рсланов Х. А. 1966. Увеличение предела датирования радиоуглеродного метода до 60-65 тыс. лет при помощи применения сцинтиллящионной методики измерения. Бюлл. комис. по опр. абс. возраста, вып. VIII. M.

А услендер В. Г., Арсланов Х. А., Гаркуша В. И. 1970. К вопросу о стратиграфии и геохронологии позднеплейстоценовых отложений Кубено-Сухоньской низины и прилегающих водоразделов. В сб.: Периодизащия и геохронология плейстоцена. Л.

В игдорчик M. Е., Ауслендер В. Г., Зн аменская О. М., Долуханов П. М. 1970а. Новые радиоуглеродные датировки озерных осадков на северо-западе: РСФСР и геохронологическая шкала последнего оледенения. Тр. Всесоюз. симп. по основным проблемам пресноводных озер, 2. Вильнюс.

Вигдорчик M. Е., Ауслендер В. Г., Долуханов П. М., 3 наменская О. М., Гайгерова Л. А., Ӓгранова Д. А., Гей В. П. 1970бь Геохронологическое и ритмостратиграфическое расчленение плейстоцена СевероЗапада Русской равнины. В сб.: Периодизация и геохронология плейстоцена. J.

Е взеров В. Я. 1970. К вопросу о возрасге межледниковых отложений Кольского полуострова. Мат-лы по геол. и металлогении Кольского п-ва. Апатиты.

3 ар рин а Е. П. 1970. Геохронология и палеогеография позднего плейстоцена на северо-западе Русской равнины. В сб.: Периодизация и геохронология плейстоцена. Л.

Ильвес Э., Пуннинг Я.-М., Лийв а А. 1968. Радиоуглеродное датирование субфоссильных костей. Изв. АН ЭССР, Биол., 17, № 4.

К ар лстрём Т. 1966. История оледенения Аляски и ее значение для теории палељклимата. В сб.: Солнечная активность и изменения климата. Л.

К аяк К., Пуннин г Я.-М., Р аукас А. 1970. Новые данные о геологии разреза Карукюла (Юго-Западная Эстония). Изв. АН ЭССР, Хим. Геол., 19, № 4.

Кинд Н. В., Алексеев В. А. 1963. Применение различных углеродсодержащих ископаемых материалов для определения абсолютного возраста по радиоуглероду. В сб.: Абсолютная геохронология четвертичного периода. М.

К и нд Н. В. 1969. Вопросы синхронизации геологических событий и колебаний климата в верхнем антропогене. В сб.: Основные проблемы геологии антропогена Евразин. М.

Л а в ров а М. А. 1960. Четвертичная геология Кольского полуострова. М.-Л.

Ор вику К. К. 1958. Литологическое исследование морены последнего оледенения Әстонии количественными методами. Тр. Ин-та геол. АН ЭССР, III.

О рви ку К. К., Пи р р у с Р. О. 1965. Межморенные органогенные отложения в Карукюла (ЭстССР). В сб.: Литология и стратиграфия четвертичных отложений Эстонин.

Пуннинг Я.-М. К., Р а ука с А. В., С ере брянный Л. Р. 1967. Геохронология последнего оледенения Русской равнины в свете новых радиоуглеродных датировок ископаемых озерно-болотных отложений Прибалтикн. Мат-лы II симп. по истории озер Сев.-Зап. СССР. Минск.

Пуннинг Я.-М. К. 1969. Применение радиоуглеродного метода для изучения истории покровного оледенения в верхнем плейстоцене и эволюцни древнебалтийских водоемов в раннем и среднем голоцене на территории Прибалтики. Автореф. канд. дисс. геол.-мин, н. Таллин. 
Пунниннг Я.-М. 1970. О погрешностях радиоуглеродного метода и о контроле достоверности полученных дат. Изв. АН ЭССР, Хим. Геол., 19, № 3.

B r o e cker W. S., Kul p J. L. 1956. The radiocarbon method of age determination. Am. Antiquity, 22, No. 1.

H a ring A., Vries A. E. de, Vries H. L. de. 1958. Radiocarbon dating up to 70000 by isotopic enrichment. Science, 128, No. 3322.

Korpela K. 1969. Die Weichsel Eiszeit und ihr Interstadial Peräpohjola (Nördliches Nordfinnland) im Licht von submoränen Sedimenten. Ann. Acad. Sci. Fennicae, Ser. A, III, Geol.-Geogr., 99. Helsinki.

Marthinussen $M$. 1962. $C^{14}$ datings referring to shore lines, transgressions, and glacial substages in Northern Norway. Norges Geol. Undersøkelse, No. 215, årbok 1961 .

O ls s o n J. U., B la ke W. 1961-1962. Problems of radiocarbon dating of raised braces, based on experience in Spitzbergen. Norsk geogr. tidsskr. 18, h. 1-2.

$\mathrm{V}$ e e h H., C h a p pel J. 1970. Astronomical theory of climatic change support from NewGuinea. Science, 167, No. 3919.

Ннститут геологии

Академии наук Эстонской ССР

Поступила в редакцию

6/I 1971

\section{J. -M. PUNNING}

\section{TEISE HILISPLEISTOTSEENI JÄAVAHEAJA ABSOLUUTSEST VANUSEST VENE TASANDIKU LOODEOSAS}

Viimastel aastatel on kogunenud palju uusi andmeid, mis kinnitavad, et hilispleistotseenis oli pärast mikuulini jäävaheaega veel teinegi jäävaheaeg. Selle kasuks räägivad ka Karuküla, Peedu, Suhona, Ponoi ja Tsapoma leiukohtadest saadud ja autori poolt radiosüsiniku meetodil määratud leidude vanused. Eriline tähtsus on Karuküla leiukohal, kust on esitatud kümme $\mathrm{C}^{14}$ meetodil tehtud dateeringut.

Suurt huvi pakuvad Koola poolsaare leiukohtadest saadud subfossiilsete kodade dateeringud, mis osutavad meretaseme eustaatilisele tõusule 30-40 tuhat aastat tagasi.

\section{J. -M. PUNNING}

\section{ON THE ABSOLUTE AGE OF THE SECOND INTERGLACIAL IN THE NW PART OF THE RUSSIAN PLAIN DURING THE LATE PLEISTOCENE}

In recent years, abundant new data have been obtained, pointing to the existence of a yet another interglacial following the Mikulino interglacial in the Late Pleistocene. This assertion is confirmed by the author's researches into the age of deposits at Karuküla, Peedu, Sukhona, Ponoi and Tsapoma, carried out with the help of the radiocarbon method. Of particular significance is the age of the Karuküla deposit. The article contains a list of ten $\mathrm{C}^{14}$ datings of the Karuküla deposit, published hitherto.

Of further interest are the datings of subfossil valves in the deposits of the Kola Peninsula, which speak of a eustatic rise of the sea level 30-40 thousand jears ago. 